\title{
Research on the Influencing Effect between CHVA and CPI in China Based on VAR Models
}

\author{
Jinge Zhou ${ }^{1}$, Juan Chen ${ }^{2}$, Xiuli Yu ${ }^{1,3}$, Yifan $\mathrm{Li}^{4}$, Qifeng Lin ${ }^{4}$ \\ ${ }^{1}$ Guangdong University of Technology School of Management, Guangzhou, China; ${ }^{2}$ Guangdong University of Technology School of \\ Economics and Trade, Guangzhou, China; ${ }^{3}$ Psychological Education and Research Department, Guangdong University of Technol- \\ ogy, Guangzhou, China; ${ }^{4}$ School of Applied Mathematics, Guangdong University of Technology, Guangzhou, China. \\ Email: 411682485@qq.com
}

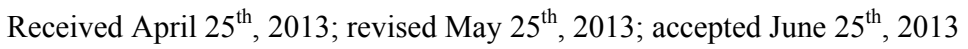

Copyright (C) 2013 Jinge Zhou, Juan Chen. This is an open access article distributed under the Creative Commons Attribution License, which permits unrestricted use, distribution, and reproduction in any medium, provided the original work is properly cited.

\begin{abstract}
The cointegration test, granger causality test, VAR model, impulse response function and other econometric methods are used in this paper to analyze the influencing effect between commercial housing vacancy rate and CPI and its delay impact. The results show that there is a long-term equilibrium relationship between commercial housing vacancy rate and CPI in China. There are at least one cointegration relationship between CHVR and CPI. The past values of the CPI appear to contain information which is useful for forecasting changes in the CHVR. CPI has a significant effect on CHVR and CPI rising drives CHVR.
\end{abstract}

Keywords: CHVR; CPI; VAR; Cointegration

\section{Introduction}

The real estate industry is a leading industry of the entire China economy and influences the quality of life of the residents. The commercial housing vacancy rate fluctuation entails real estate with commodity house prices. In recent years, the price of China's real estate has improved extremely, and CPI also increased sharply. Hence, some scholars believe that the commercial housing can't avoid the risk of inflation.

In the past few years, both domestic and overseas researchers made an empirical analysis of the relationship between the real estate and CPI. Raymond's thesis showed that there is no causal relationship between land supply and housing prices and their estimations, which based on the annual data of Hong Kong's public land sales, found that the government acts to maximise land revenue [1]. Jack H. Rubens, Michael T. Bond and James R. Webb believed that assets have the ability to protect investors from the effects of inflation are generally labelled inflation hedges; the real estate has been regarded as one of the best inflation hedges of past years [2]. Willian $\mathrm{C}$. Wheaton holds the view that the vacancy rate, fixed in the short run, determines the expected length of sale and search, which plays a central role in the reserva-

${ }^{*}$ This is an extended version of the paper at the 2011 International Conference on Networks and Information. tion prices of buyer and seller [3]. SHEN Yue and LIU Hong-Yu researched the relationship between the real estate development investment and GDP in China [4]. ZHOU Zhi-Chun, LI Zheng and MAO Jie researched how real estate industry corresponds to economic vicissitudes, which is an empirical analysis based on Chinese data [5]. WANG Yao-Wu, Jin Haiyuan considered the real estate supply and land supply is the most important factor. They also thought the second important factor is the interest rate [6].

To conclude, both domestic and overseas reseachers made an empirical analysis of the relationship between real estate and CPI. However, related researching did not underline the commercial housing vacancy rate, which is the cornerstone of China real estate market. According to the fact above, this paper made some research from the perspective of effect size and effect time lag between commercial housing vacancy rate and CPI on China real estate market. The research is of positive value and political reference under the back ground of China's current economic system and real estate industrial integration.

\section{Data Processing}

All data series are annually begins in 1995 and ends in 2010, it shows by Table 1. Data on China's CHVR (which is commercial housing vacancy rate) and consumer 
Table 1. 1995-2010, China’s CHVR and CPI's annual data.

\begin{tabular}{cccc}
\hline Years & CHVR & $\begin{array}{c}\text { The chain } \\
\text { growth of } \\
\text { CHVR }\end{array}$ & $\begin{array}{c}\text { The chain } \\
\text { growth of CPI }\end{array}$ \\
\hline 1995 & 0.1209 & 0.0239 & 0.5450 \\
1996 & 0.1397 & 0.0188 & 0.5170 \\
1997 & 0.1654 & 0.0257 & -0.0500 \\
1998 & 0.1802 & 0.0148 & -0.1330 \\
1999 & 0.1960 & 0.0158 & -0.1580 \\
2000 & 0.1670 & -0.0290 & 0.0250 \\
2001 & 0.1540 & -0.0130 & -0.0330 \\
2002 & 0.1400 & -0.0140 & -0.0330 \\
2003 & 0.1400 & 0.0000 & 0.2670 \\
2004 & 0.1179 & -0.0221 & 0.1920 \\
2005 & 0.1211 & 0.0032 & 0.1330 \\
2006 & 0.1010 & -0.0201 & 0.2330 \\
2007 & 0.0820 & -0.0190 & 0.5330 \\
2008 & 0.0950 & 0.0130 & 0.1080 \\
2009 & 0.1083 & 0.0133 & 0.1420 \\
2010 & 0.1130 & 0.0047 & 0.3750 \\
\hline
\end{tabular}

prices (CPI) are all from the China National Bureau of Statistics (CNBS).

Because of the data acquisition is more difficult. We use the annual data. This could have an impact on the accuracy of the article.

\section{Empirical Analysis}

\subsection{Unit Root Test}

The ADF test was the first test developed for testing the null hypothesis of root and was the most commonly used test in practice [7].

This value is just under less than $5 \%$ critical value in Table 2. CPI and CHVR are stationary time series. So we can undertake next inspection. Because the serials are same-order single integral serial. Hence, we can further test the long-term equilibrium relationship between all variables.

\subsection{VAR Model's Cointegration}

Two time series with stochastic trends can move together so closely over the long run that they appear to have the same trend component, that is, they appear to have a common trend, which are said to be cointegrated [7]. In this section, we introduce a test for whether cointegration is present.

CHVR and CPI share a common stochastic trend, because their prod under 0.05 , it shows by Table 3 . The spread or the difference between the two rates does not exhibit a trend. They appear to be cointegrated. According to the cointegration test results we can estimate that there are at least one cointegration relationship between CHVR and CPI.

\subsection{Granger Causality Test}

One useful application of the F-statistic in time series forecasting is to test whether the lags of one of the included regressors has useful predictive content, above and beyond the other regressors in the model. The claim that a variable has no predictive content corresponds to the null hypothesis that the coefficients on all lags of that variable are zero. This is called the Granger causality statistic, and the associated test is called Granger causality test [8].

We consider the relationship between the CHVR and CPI. Based on the OLS estimates (Table 4), the F-statistic testing the null hypothesis that the coefficients on all lags of the CPI is $3.83(p<0.1)$ : we can conclude (at the 0.1 significance level) that the CPI Granger-causes changes in the CHVR. It do means that the past values of the CPI appear to contain information that is useful for forecasting changes in the CHVR, beyond that contained in the past values of the CHVR.

\section{VAR Model Estimation}

Vector autoregression (VAR) is a set of $\mathrm{k}$ times series regressions, in which the regressors are lagged values of all $\mathrm{k}$ series. A VAR model extends the univariate autoregression to a list, or "vector", of time series variables. The equation is called a VAR model.

Table 2. ADF test results.

\begin{tabular}{ccc}
\hline & $\begin{array}{c}\text { value } \mathbf{5 \%} \text { level } \\
\text { critical value }\end{array}$ & Conclusion \\
\hline CPI & -2.20 & Stable \\
CHVR & -2.67 & Stable \\
\hline
\end{tabular}

Table 3. Johansen cointegration test results.

\begin{tabular}{|c|c|c|c|c|}
\hline \multicolumn{2}{|c|}{ Hypothesized } & \multirow{2}{*}{$\begin{array}{c}\text { Trace } \\
\text { Statistic }\end{array}$} & \multirow{2}{*}{$\begin{array}{l}0.05 \text { Critical } \\
\text { Value }\end{array}$} & \multirow{2}{*}{ Prob. } \\
\hline No. of CE (s) & Eigenvalue & & & \\
\hline None & 0.50 & 15.77 & 12.32 & 0.01 \\
\hline At most 1 & 0.35 & 6.01 & 4.13 & 0.02 \\
\hline
\end{tabular}

Table 4. Test results of granger causality.

\begin{tabular}{cccc}
\hline Null Hypothesis & F-Statistic & $\begin{array}{c}\text { Associated } \\
\text { Prob. }\end{array}$ & Conclusion \\
\hline $\begin{array}{c}\text { KONG does not } \\
\text { Granger Cause } \\
\text { CPI }\end{array}$ & 0.45 & 0.65 & $\begin{array}{c}\text { Agree null } \\
\text { hypothesis }\end{array}$ \\
$\begin{array}{c}\text { CPI does not } \\
\text { Granger Cause } \\
\text { KONG }\end{array}$ & 3.83 & 0.06 & $\begin{array}{c}\text { Refuse null } \\
\text { hypothesis }\end{array}$ \\
\hline
\end{tabular}


In the case of two time series variables, $Y_{t}$ and $X_{t}$, the $\operatorname{VAR}(p)$ consists of the two equations:

$$
\begin{aligned}
Y_{t}=\beta_{10} & +\beta_{11} Y_{t-p} \\
& +\cdots+\beta_{1} Y_{t-p}+\gamma_{11} X_{t-1}+\cdots+\gamma_{1 p} X_{t-p}+\mu_{1 t} \\
X_{t}=\beta_{20} & +\beta_{21} Y_{t-1} \\
& +\cdots+\beta_{2 p} Y_{t-p}+\gamma_{21} X_{t-1}+\cdots+\gamma_{2 p} X_{t-p}+\mu_{2 t}
\end{aligned}
$$

where the $\beta$ 's and $\gamma$ 's are unknown coefficients and $\mu_{1 t}$ and $\mu_{2 t}$ are error terms.

The VAR assumptions are the time series regression assumptions of Key Concept (1), applied to each equation. The coefficients of a VAR are estimated by estimating each equation by OLS [9].

The system is estimated with annually data from 1995 to 2010, under the baseline system. In selected period, we are constrained it by the availability of data for the China National Bureau of Statistics. As suggested by the relevant lag selection criteria (Akaike Information Criterion, Schwartz Bayesian Criterion) we use two lags. The CPI allows for a contemporaneous response of the CHVR (In the Figure 1 the red lines mean error bars, the blue one mean line of impact).

The orthogonalized residuals of the CPI equation are identified as CHVR. Figure 1 reports, over a period of
10 years, the impulse responses of CPI to a one standard deviation shock in the CHVR equation. The main results of this contractionary shock on the other variables in the system can be summarized as follows:

CPI has a great influence on the CHVR. When the CPI rises, the vacancy rates increase accordingly. The response of CPI to CHVR is significant negative response appears firstly - as the CHVR level rises gradually to reach a trough two years after the initial shock. The decline becomes significant after three years. Finally, CHVR decreases steadily after the seven years to reach its lowest level in the three years, and returns to its pre-shock level ten years after CPI impulse.

The response of the CHVR to CPI is smaller in magnitude than the response of CPI to CHVR. More importantly, the shock dies out very quickly, five years after the initial impulse so that there is no innovation paradox.

\section{Summaries}

The results show that there is a long-term equilibrium relationship between CHVR and CPI in China. There are at least one cointegration relationship between CHVR and CPI. The CPI Granger-causes changes in the CHVR. It is certain that the past values of the CPI appear to contain information that is useful for forecasting changes in

Response to Cholesky One S.D. Innovations \pm 2 S.E.

Response of KZL to KZL

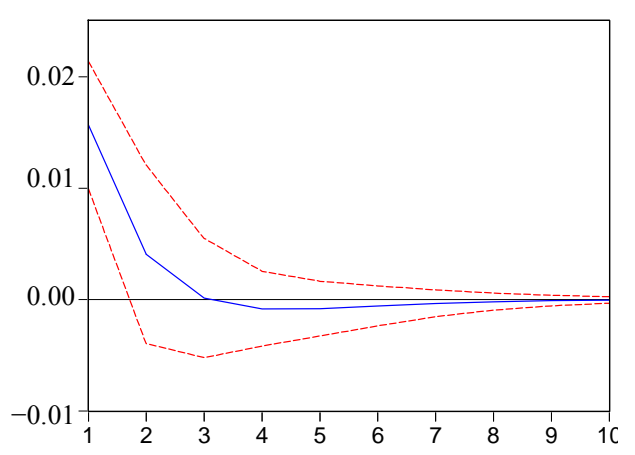

Response of CPI to KZL

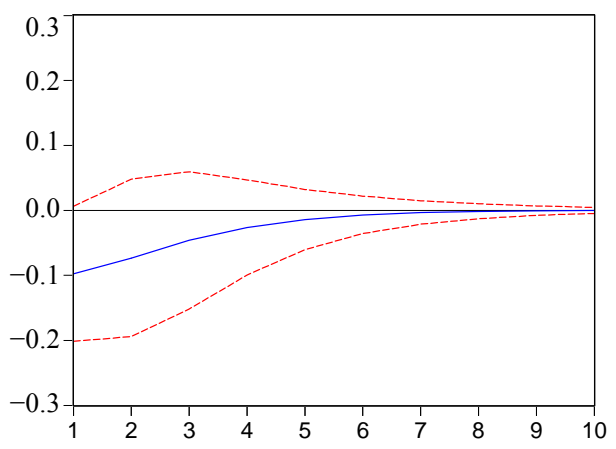

Response of KZL to CPI

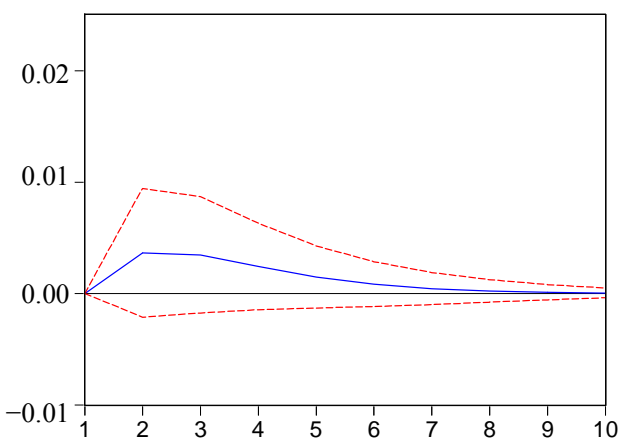

Response of CPI to CPI

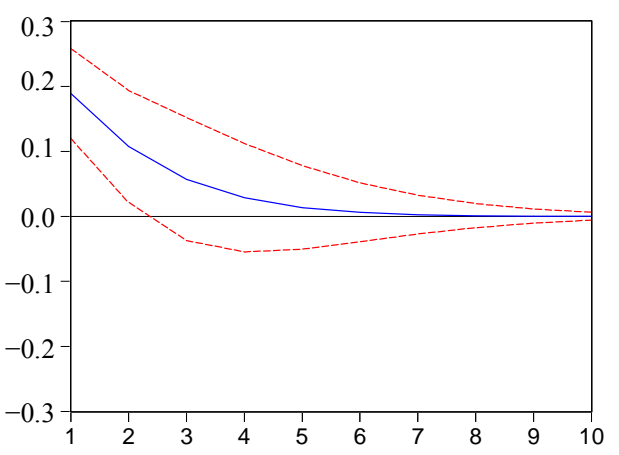

Figure 1. Impulse responses to a CHVR shock-system with CPI (1995-2010). 
the CHVR, beyond that contained in the past values of the CHVR, not vice versa. CPI has a great influence on the CHVR. When the CPI rises, the vacancy rates increase accordingly. The response of CPI to CHVR is significant response appears for the first-as the CHVR level rises gradually to reach a trough two years after the initial shock. The decline becomes significant after three years. Finally, CHVR declines steadily after the seven years to reach its lowest level in the three years, and returns to its pre-shock level ten years after CPI impulse.

\section{REFERENCES}

[1] Y. C. Tse Raymond, "Housing Price, Land Supply and Revenue from Land Sales," Urban Studies, Vol. 35, No. 8, 1988, pp. 1377-1392.

[2] J. H. Rubens, M. T. Bond and J. R. Webb, "The Inflation-Hedging Effectiveness of Real Estate," Journal of Real Estate Research, Vol. 2, 2009, pp. 45-55.

[3] W. C. Wheaton, "Vacancy, Search, and Prices in a Housing Market Matching Model," The Journal of Political Economy, Vol. 98, No. 6, 1990, pp. 1270-1280. doi: $10.1086 / 261734$
[4] Y. Shen and H.-Y. Liu, "The Relationship between Real Estate Development Investment and GDP in China," Journal of Tsinghua University (Science and Technology), Vol. 44, 2004, pp. 1205-1208.

[5] Z.-C. Zhou, Z. Li and J. Mao, "Researched How Real Estate Industry Corresponds to Economic Vicissitudes? An Empirical Analysis based on Chinese Data," Journal of Nanting University, Vol. 47, 2010, pp. 47-57.

[6] Y.-W. Wang and H. Y. Jin, "An Empirical Analysis of the Impart of Real Estate Macro-Control Policy," China Civil Engineering Journal, Vol. 41, 2008, pp. 105-114.

[7] J. H. Stock and M. W. Watson, "Introduction to Econometric," Shanghai University of Finance Economics Press, Shanghai, 2004, pp. 448-463

[8] C. W. J. Granger, "Investigating Causal Relations by Econometric Models and Cross-Spectralmethods," Econometrica, Vol. 37, No. 3, 1969, pp. 424-438. doi:10.2307/1912791

[9] H. H. Pesaran and Y. Shin, "Gneralized Impulse Response Analysis in Linear Multivariate Models," Economics Letters, Vol. 58, No. 1, 1998, pp. 17-29. doi:10.1016/S0165-1765(97)00214-0 